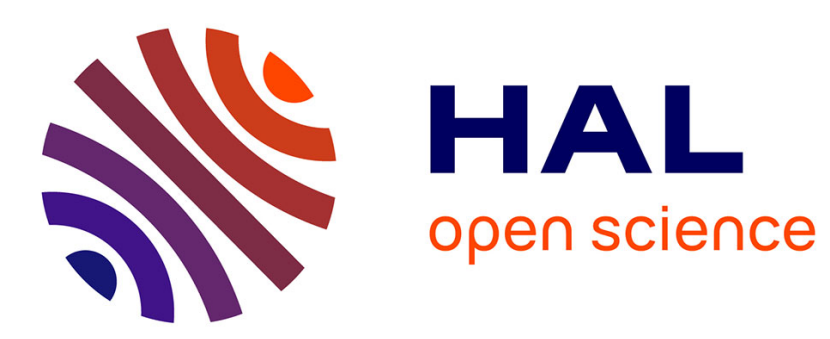

\title{
The Decentralisation of Airbus Production and Services
}

\author{
Marie-Christine Longe Monnoyer, Jean-Marc Zuliani
}

\section{To cite this version:}

Marie-Christine Longe Monnoyer, Jean-Marc Zuliani. The Decentralisation of Airbus Production and Services. Service Industries Journal, 2007, 10.1080/02642060701207056 . hal-02542839

\section{HAL Id: hal-02542839 \\ https://hal.science/hal-02542839}

Submitted on 22 Apr 2020

HAL is a multi-disciplinary open access archive for the deposit and dissemination of scientific research documents, whether they are published or not. The documents may come from teaching and research institutions in France or abroad, or from public or private research centers.
L'archive ouverte pluridisciplinaire HAL, est destinée au dépôt et à la diffusion de documents scientifiques de niveau recherche, publiés ou non, émanant des établissements d'enseignement et de recherche français ou étrangers, des laboratoires publics ou privés. 


\title{
The Decentralization of Airbus Production \& Services
}

\author{
MARIE-CHRISTINE MONNOYER ${ }^{1}$ AND JEAN-MARC ZULIANI ${ }^{2}$
}

\begin{abstract}
Airbus has been multisourcing production since the first rollouts in the late 1970s, spawning clusters of suppliers around its locations in Bristol, Hamburg, Madrid and Toulouse. Moreover, both the A380 project and globalization of the aircraft market pointed up the need and value of outsourcing. We analyze the outlook for supplier clusters in Toulouse and elsewhere based on Airbus thinking and practices before identifying the ingredients of successful outsourcing
\end{abstract}

Key words : outsourcing, services, Airbus, production models, cluster, centers of excellence, decentralization

\section{INTRODUCTION}

Airbus reconstituted as an S corporation in 2001 (société par actions simplifiée) with four shareholders of different nationalities. The head office ${ }^{3}$ is in Toulouse, France. The Toulouse plant handles final assembly, ground/flight testing, airworthiness certification, marketing and customer services, backed up by additional production facilities in Germany, Spain and the United Kingdom and elsewhere in France, which integrate $\mathrm{R} \& \mathrm{D}$, sub-assembly and quality control of components. The first salient feature of the production setup is that most locations host R\&D performed by both Airbus and local suppliers. Second, Airbus and sub-assembly suppliers concentrate manufacturing, testing and final quality control activities at or around these locations. Both the R\&D and manufacturing operations underscore the supervisory role of Airbus, which operates at the local, national and international levels to develop new organization models for production.

Even against the backdrop of globalizing national economies, the Airbus production setup is original. This surely reflects its birth as a consortium ${ }^{4}$ in 1969 and subsequent restructurings designed to merge several European firms into a single unit despite their strong corporate cultures and differing areas of expertise that were not always complimentary (Muller 1989). However, Airbus is now European in a very real way: headquarters employees in Toulouse alone span 30+ different nationalities and its client base covers $100+$ countries. This makes it an open-ended player on world markets. Nonetheless, Airbus options are heavily influenced by the French and German business mindsets, powerful labor unions and ongoing relationships with national and local governments. So how does this context affect the extension of outsourcing to non-European suppliers? Does this qualify as going offshore? After

\footnotetext{
${ }^{1}$ Institut d'Administration des Entreprises (CRG, Université Toulouse 1), LERASS

${ }^{2}$ Université Toulouse-Le Mirail, CIRUS-CIEU (UMR 5053 of CNRS)

${ }^{3}$ Appendix 1: EADS Organization Chart

${ }^{4}$ It incorporated as a "groupement d'intérêt économique", i.e. a body with a legal constitution, comprised of at least two physical or moral persons with joint and several liability set up to further separate or common activities.
} 
tracking Airbus expansion over several years and contacts with a wide variety of its staff, we realized that the firm has done some hard strategic thinking about its 'make or buy' policy since 2003 .

Any single case study will provide only limited insight and answers to the actual practices, setups and impact of international outsourcing, which is a major issue to the aeronautics industry because of its production and organizational needs. We therefore identified it as a particularly interesting focus of study. In the European Union, it is concentrated in a handful of countries and locations that have become heavily dependent upon it for economic growth and employment (Vekeman 2006). Across Europe, its gross operating margins exceed those of the manufacturing industry, generating comfortable profits that make for operational freedom of action. However it is very dependent on subcontractors for goods and services, which account for $60 \%$ to $80 \%$ of the output value of intermediate inputs (Vekeman 2006). Finally, the European aeronautics industry is on the frontlines of international competition and despite the export surge in recent years, the 25 E.U. members still show a negative trade balance with the U.S.A. We might further note that outsourcing of services is all the more critical for Airbus and the aeronautics industry because of the scale of the capital investments involved and its impact on the technology and processes of aircraft production (Cunat and Thomas 1994). This paper aims to provide food for thought based on our understanding of the Airbus operation. We begin with a review of that decentralized production setup and its recent development before examining new strategies for the purchase and subcontracting of services.

\section{STRATEGY AND OPERATION OF THE EXTENDED NETWORK CORPORATION}

Aircraft manufacture divides into upstream activities such as basic research, $R \& D$, training and services and into increasingly important downstream activities such as finance, sales, marketing, customer services and maintenance. It assumes complex interactions among its constituent entities. Beyond the complimentary relationships among different production plants, the structure of local interactions among various sub-activities affects the production of the aeronautical product in each location, be it in R\&D or further down in production and assembly. However we need an overall grasp of changes to the Airbus production macroapparatus if we are to obtain a proper understanding of local production setups and any restructuring of supply and demand for technological services.

\section{The Rise of Airbus as an Integral Member of the EADS Group}

Geographical distribution was a feature of Airbus production model ever since it turned out its first airliners in the late 1970s while climbing demand and a growing number of aircraft families induced the model to continue evolving, e.g. start-up of medium-haul production lines in Hamburg. Yet the model itself still survives. Wing manufacture happens in Bristol and Chester, U.K. Aft and center fuselages are made and assembled in Hamburg, Germany while forward fuselage sections come from Nantes and St. Nazaire in France. High-speed machining technology turns out leading edge components in Méaultes, France. Final assembly and ground/flight testing are performed in Toulouse, France where the entire forward section comes together, i.e. cockpit and avionics. Toulouse makes the critical nacelles and pylons that strap the 
turbofans to the wings as well as the fuel regulators and wirings. Rudders and vertical stabilizers are made in Getafe and Madrid, Spain, which have mastered carbon fiber technology.

\section{Insert Diagram 1. A321 Manufacturers}

Structural considerations led Aérospatiale-Matra in France, CASA in Spain and DASA in Germany, to merge into EADS, obtaining a single European aerospace manufacturer. The merger aimed to (1) reach critical mass by integrating E.U. production of fixed-wing aircraft, helicopters, missiles and spacecraft; and (2) partially privatize the corporation as a pre-requisite to Europeanization. Henceforth, civil aviation is the exclusive preserve of Airbus Integrated Company (AIC), where ownership is $80 \%$ EADS and $20 \%$ BAE Systems. S corporation status and shareholder equity enabled AIC to make direct capital investments and subsequently double its registered capital. The EADS merger obtains a market-driven corporation with dividend-minded shareholders where new aircraft projects stand or fall on their earnings potential (Zuliani, Jalabert and Leriche 2003).

\section{The Impact of the Airbus Production Setup on the A380 Project}

\section{Task Allocation by Center of Excellence}

The creation of AIC led to constitution of an integrated organization with a unique, unavoidably complex management of programs by individual aircraft families with headquartering of financial operations in Toulouse. However, integration requires interactive organization charts for each product and country that crisscross in different sectorial and production directions. The current AIC setup is based on 10 areas of technical expertise that reflect the specialized know-how proper to each "center of excellence" (CoE) in France, Germany, Spain and the United Kingdom.

The next issue is the territorial distribution of industrial and service skills. That distribution determines the organization of AIC production in Europe. Each of the four national operations just cited focuses on a territorial specialization, consolidates its local position, builds up know-how and exploits feedback. The CoE concept assumes ongoing upgrade of specific expertise, whence the stress on R\&D at each $\mathrm{CoE}$ and a high demand for the services of engineering consultancies and institutes of applied research. Each $\mathrm{CoE}$ has to run its own ship, innovate and optimize its margins. The creation of AIC has enabled each European $\mathrm{CoE}$ to focus design and innovation efforts on a given core activity, thus also enabling it to organize a local or regional network of subcontractors, with know-how transfers to select subcontractors who, in turn, organize supply networks of their own. It then remains to coordinate inter-CoE activities and to interconnect their specific functions, i.e. to manage the components of the AIC corporate network in Europe (Zuliani, Jalabert and Leriche 2003).

\section{The Growing Importance of $R \& D$ Services}

The AIC networked corporation shows a global trend of usually gradual build-ups over time of R\&D capabilities at all locations. We wondered about the effects at each one. First, we note the benefit of closer ties to government laboratories and of recourse to suppliers of IT \& design engineering services. We also see restructuring of intercompany relations and the allocation of global tasks to avionics suppliers who handle all their own R\&D. This has the following two consequences: 
- Increasingly specialized tasking between locations such that each handles what it does best, e.g. Toulouse drafts specifications and, more critically, obtains airworthiness certification for the fly-by-wire software that differentiates it from Boeing, its key competitor.

- The build-up of sets of R\&D specializations that cover a given production task, which in turn upgrade research capabilities in its area(s) and explain the increasingly global trend into specialization by location.

The R\&D effects of specialization in each sector are visible at each location. Based on its track record as prime contractor for the Caravelle (the world's first jetliner), Concorde and the Airbus families, Toulouse is the lead location for engineering and sales/marketing: the design bureau employs 2,500 staff and the AIC head office, another 3,000+. The Toulouse operation both (1) coordinates all aeronautical programs throughout the R\&D process where it periodically hosts 'platform team' meetings for all its partners in order to monitor project status and production tooling, a function that fostered the development of support services for design engineering and facilities management systems, and (2) designs and integrates avionics and flyby-wire software - the cutting edge of aircraft making today where workload is booming and costs account for $1 / 3$ of an aircraft's total price as avionics mobilize an army of software developers.

The differentiation process has evolved over a $20+$ year period, very gradually from one Airbus project to the next. Upstream IT services gravitated into Toulouse because of their relevance to R\&D and to its local equipment suppliers (Zuliani 2005). Moreover, these activities also trickled out from AIC locations into the neighboring countryside, stimulating the growth of many smaller manufacturers. Encompassing a radius of $150 \mathrm{~km}$ around Toulouse, the Midi-Pyrénées administrative region contains scores of industrial subcontractors involved in the manufacture and testing of aircraft parts. The same applies to northern Germany and task specialization among plants in and around Bremen, Stade, Varel or Hamburg which puts together the vertical tailplanes as well as the center and forward fuselages but also performs final integration of the short-haul A318, A319 and A321 models. Because of the need for a close working relationship between AIC and its key equipment suppliers, both Hamburg and Toulouse have evolved major local networks of consultancy and engineering services based in their metropolitan areas.

These fully interdependent client/supplier relationships have fostered the development of the extended corporation (Zuliani 2004). Founded upon the aircraft maker's complex activities, a series of intellectual and organizational links pin down AIC in a hierarchy of industrial and engineering suppliers that bundles partners according to standardized working methods, with liaison representatives from corporate partners on each other's sites and shared, standardized IT resources. The new outsourcing management policy for goods and services is the result of the creation of an integrated corporate operation through networks that span multiple European locations and of rising aircraft deliveries that reflect the commercial success of its leading aircraft families. The globalized management of the most recent A 350, A380 and A400M projects, plus the requirement to slash $20 \%$ to $30 \%$ off production costs, has focused attention on the local fabric of IT and technological 
services as well as downstream customer services. Each of the three faces unique challenges to globalization that imply new forms of division of labor.

\section{TASKING AND RESTRUCTURED SUBCONTRACTING}

\section{AIC Incentives to Restructure Subcontractor Relationships}

The A380 project will be remembered for triggering a spate of new AIC purchasing policies. The new policies apply to all suppliers of goods and services aim to slash purchase costs with a view to boosting margins and handling bigger order volumes.

Outsourcing amounts to $70 \%$ of equipment costs and $50 \%$ of airframe costs of an A380. Consequently, subcontract management will become increasingly important as those two figures continue to rise. Cost control requires intensifying the competition between suppliers. Centralized purchasing from a single location should strengthen bargaining positions by enabling bigger orders at lower unit prices. The 10 areas of technical expertise are each managed by a 'Procurement V.P.' at the head office, who holds a key strategic role in supplier contract management. Although these measures allow each CoE to contract for supplies itself, such local initiatives are routed through the AIC head office in the interests of overall coherence and efficacy. This global approach to profitability therefore operates against close ties between national AIC locations and their local suppliers of goods and services.

However, growing markets are inducing (1) ever greater downstream needs for training and maintenance and upstream needs for quality control of supplier output and raw materials, which both require onsite presence, and (2) increasing pressure for offset purchases, which means accepting tenders from new outsiders. ${ }^{5}$

Therefore, any approach to outsourcing must operate such that it satisfies the qualitative demand for expertise and physical proximity as well as the quantitative issue of offset purchases. In addition, the value of a service is not in its materials. Unlike manufactured goods, the value of a service depends entirely upon its effect(s) (Barcet and Bonamy 1994). Inclusion of new suppliers may enhance or erode the flexibility or competitiveness of a given service. It can even affect AIC's relationship with airlines inside the service supplier's zone of influence as well as with pilots, mechanics and others with a voice in aircraft purchases. No longer a mere tool of cost savings, outsourcing also qualifies as an investment in that the effects of the purchased services extend over time, especially where they affect products with a long service life (Barcet and Bonamy 1994). Immediate cost savings are no longer necessarily the key concern (Fimbel 2003).

\footnotetext{
5 :

'Offset sales' are contractual arrangements in international arms sales in which arms manufacturers agree to guarantee a certain percentage of the total purchase price in return business. The first instance was U.S. sales of F-104G/J fighters and Hawk missile systems in the 1950s to Germany and Japan. 'Direct' offsets involve partial or complete manufacture of the weapon in the purchasing country whereas 'indirect' offsets cover return business in unrelated items. Offsets inject anything up to $130 \%+$ of the purchase price into the purchaser's national economy and reduce the foreign exchange costs of the imported systems.
} 
The issue of AIC needs and the nature of its relationships to suppliers led to benchmarking of existing practices at its different production facilities. It became quickly apparent that the culture of the host country exerts a powerful influence on how IT outsourcing happens and its limits. U.K. locations outsourced services far more than French ones and Germans, the least of all. They also tended to deal in bigger contracts with distant suppliers while larger numbers of small contracts with numerous local suppliers sooner typified the French and German operations.

We also benchmarked the purchase of services by other aircraft manufacturers and major outsourcers. This showed the dynamic approach of some IT service providers who operate platforms in Toulouse and now also subcontract to AIC suppliers in Hamburg and Toulouse in order to provide remote information management and facilities management services to non-European aircraft builders such as Bombardier and Embraer.

Increased purchases and the quest for first-rate suppliers has caused AIC to adopt 'make-or-buy' policy for both services and proper manufactured goods.

\section{Make-or-Buy Practices}

The impact of outsourcing on the total AIC operation, the specific constraints of the aeronautical industry and our approach to the subject lead us to examine outsourcing in ways that go beyond the theory of transaction costs.

An aircraft maker's airworthiness liability spans the entire service life of each of its products. Any outsourcing of avionics equipment, fly-by-wire software or maintenance does not authorize data losses or erosion of know-how. This also holds for the outsourcing of quality control and software development by subsystems suppliers.

Applied to services, make-or-buy strategy examines the feasibility of in-house performance of a given type of service as well as each of its elements and the impact of that (type of) service on AIC activities as a whole, e.g. outsourcing may undermine in-house capability to co-perform the service with a supplier.

The choice of a supplier is based not only on his ability to provide but also on issues of organizational efficacy and innovative potential, which will spin off positive effects for AIC.

AIC suppliers must meet certain minimums: ISO 9002 certification or CMMI 3 for direct suppliers of IT services, use of EDI or other state-of-the-art tools, demonstrated responsiveness to AIC needs and an ongoing capability to innovate.

AIC outsourcing strategy for the supply of aircraft modules aims to restrict direct subcontracts to a core of suppliers because the workload of monitoring suppliers is not proportional to their size and interactions with large numbers of suppliers would consume enormous amounts of AIC management time. For the same reason, AIC relies increasingly on off-the-shelf purchases and real-time information sharing with direct subcontractors and suppliers. 
An accompanying strategy is to work with suppliers who can share risk and invest in new aircraft projects. This assumes the supplier has reached the critical mass needed to handle, say, entire R\&D projects. This has also increased the number of corporate groups in the subcontractor portfolio, e.g. Latécoère and SNECMA and put pressure on smaller firms to form consortiums.

\section{Effect of Make-or-Buy on Suppliers}

\section{Stratification of Suppliers}

For engineering services, make-or-buy has resulted in the creation of a class of preferred supplier-partners. These are mostly major national corporations or multinationals with specific skills or production capacity they supply under contract. Some direct suppliers such as Arck Ingénierie and Sogéclair have formed corporate groups based in the Toulouse greater metropolitan area. They have avoided centralizing their operations with a view to gradually honing their skills through direct contact with AIC since the days of Aérospatiale, its predecessor. As AIC centralizes purchase of engineering services, these groups aim to establish subsidiaries at AIC locations in Bristol, Hamburg and Madrid, if they have not already done so. However, only information systems developers operating as corporate groups can meet AIC's requirement for standardized services throughout all production facilities.

In engineering services, AIC expects the subcontractor not only to design assemblies and sub-assemblies, but also cover the financing, $\mathrm{R} \& \mathrm{D}$, testing and delivery subject to cost reduction clauses and tight delivery schedules. ${ }^{6}$ After certification by AIC, these suppliers provide not only consultant engineers to AIC design teams but also inject specific know-how and perform calculations in their fields. Some groups have even roped in smaller consultancies that have grown up around individual locations and supplied specialized skills since the early phases of AIC expansion.

Thus, the current A380 project, and the policies it spawned, led to a concentration of key subcontractors in Toulouse, Madrid and Hamburg as well as upgrade of local design engineering services (Zuliani, Jalabert and Leriche 2003). This clustering process overlaps with 'regional' upgrades of the 'extended corporation'. There is further background support from local engineering schools and university training centers while, more recently, specialized research institutes have come onstream, all of which have cultivated close ties to AIC locations. These ties include internships for $\mathrm{PhD}$ students, postgraduate engineering courses by AIC staff and the founding of university chairs.

\section{Globalized Partnerships}

The current setup does not preclude subcontracting far afield. AIC cost-cutting pressure encourages design engineering suppliers to outsource serial $R \& D$ to countries where high skills are more affordable. Several already perform routine calculations through subsidiaries in Morocco, Romania and Slovakia. These new relationships mark the beginning of globalized $R \& D$ procurement that frees AIC from the constraints of localized outsourcing. In either case, these sub-subcontractors have

\footnotetext{
${ }^{6}$ Shouldering all these responsibilities suggests that such suppliers qualify as "enablers", which Barreyre (1982) defines as "subcontractors who duty is to co-produce with the prime contractor."
} 
no direct contact with AIC and they absorb the cost cuts although AIC does monitor their performance, quality and compliance with the specification sheets, even in the case of globalized production and especially so for IT and design engineering services. Moreover, AIC imposes geopolitical limits on proprietary software development, which it keeps inside the NATO perimeter.

Meanwhile, AIC continues to seek out new suppliers of goods and services outside its traditional stalking grounds. This is because of the increasing demands of new projects but AIC's high standards of technology and quality instantly reduce the number of potential suppliers at the outset. Therefore AIC has had to mentor some potential suppliers over several years to help them qualify. In addition, cross-cultural gaps complicate human interaction and slow down integration into the AIC supplier network. For example, Russia offers a wealth of first-rate skills and design engineering suppliers that facilitate relations with potential industrial suppliers where complete subcontracting tenders are easily packaged while India shows a breadth of cultural divides that complicate outsourcing, even in IT services, at which India excels. Making these teams operationally self-sufficient involves a local presence of engineers and technicians, i.e. a substantial long-term investment of human and financial resources. However, AIC already harvests first-rate expertise from a handful of Indian firms as it develops new monitoring strategies suited to this new breed of offshore supplier.

Finally, the globalization of the aircraft market has generated new service needs. The need to localize customer services has caused AIC to set up national sales \& support centers for aircraft operators in China and the USA. It has also established national spare parts and training centers with a view to locking in its client base. However, AIC has elected to subcontract maintenance \& repair to various firms around the world rather than invest in proprietary facilities.

Thus, the decision to secure a local presence and establish the Asia/Pacific and North American regional centers establishes the methodology for deployment of a worldwide customer services network.

\section{Decomposition of the European Clusters?}

Is AIC outsourcing a serious threat to the economic development of the greater metropolitan areas and regions of Europe that have hosted its activities for the past two decades? Any answer should begin with a close look at the network of 'clusters' set up by AIC and this paper focuses on the Toulouse cluster because of our familiarity with it. This cluster has evolved gradually around AIC (and its predecessor Aérospatiale) over a period of 35 years. Backed by a substantial infrastructure of universities and engineering schools, AIC and a handful of subcontractors reached critical mass to handle entire airliner development projects. Although the grapevine attracted some players through what Farelle and Saloner (1986) call the 'penguin effect', 7 the main drive behind build-up of the cluster was the potential synergy between the towering aircraft maker and the suppliers of goods and services. Meanwhile, there was a handy educational platform dedicated to aeronautics that

\footnotetext{
${ }^{7}$ This is the tendency of a flock of penguins to follow the leader straight into the water in blind faith of finding tasty fish.
} 
supplied a pool of skilled labor and opened channels of cooperation with local research bodies to enhance expertise in avionics and fly-by-wire software.

The Toulouse production cluster grew up around the need to turn out the flyaway product. Although its principal activity is the integration of aircraft modules and avionics, that powerful platform of IT and communications know-how around AIC has been disintegrating the top-down approach to developing IT systems and design engineering services. The interactive ties among the various players generate grapevine information that improves individual competitive positions. As shown by Antonelli (1995) or Capello and Nijkamp (1995), timely information is vital to hi-tech suppliers so that they can inject input early into the process of formulating new industry standards and product compatibility.

Interestingly, suppliers have clustered around AIC at each of its European locations. This reflects the power of the professional grapevine in terms of information flow and industrial cooperation, wherein physical proximity responds to the need for circulation of tacit awareness (Suire and Vicente 2004).

Here we find the conclusions of studies in economic geography that investigate the territorial expression of industrial activity. They stress the importance of proximity for its positive impact on production processes, information sharing and coordination among neighboring firms in a given area or locality (Gilly JP and Torre A, 2000). Proximity facilitates compliance with IT hard/software compatibility requirements that go right down to joint adoption of specific versions of a given software, e.g. Catia $\mathrm{CAD} / \mathrm{CAM} / \mathrm{CAE}$. Theoretical considerations of intellectual property rights thus give way to intensive information sharing and long-term trust among suppliers. The organizational proximity loops back to enhance both skill levels and competitiveness all around.

In the case of the AIC clusters, research into outsourced R\&D points out that physical proximity facilitates coordination and information flow between players and prevents erosion of technological capabilities (Saxenian 1994 cited in Dumoulin and Martin 2003).

But how stable are these clusters? In their comparison of Silicon Valley CA to Silicon Sentier in Paris, Suire and Vicente (2004) showed that industrial interdependence formalized by a network of contracts, enhances the appeal of a location and consolidates the market positions that member enterprises already held on their greater metropolitan or regional niche markets. At the greater metropolitan level, each location offers a set of specific relational resources that would make it costly for any member to move out. This internal cohesion promotes innovation and stimulates the creation of added value. But does this suffice to restrict outsourcing to a demand for services that exceed in-house capacity or capabilities? It appears that AIC applies intrinsic rules of physical proximity to IT services as part of their policy and practices for upstream tasks of specifications design and testing of the highly specialized systems proper to aeronautics.

This study also looked at the present status of the 1990s trend into seeding when a good number of Airbus engineers went freelance, using their in-house skills to develop services that matched AIC needs. They also exploited their personal 
connections to lock in solid business relationships. But is the current trend into mergers and acquisitions demotivating independent young talent or restricting their direct access to AIC? After reviewing avionics developers, who are on the leading edge of the A380 program, our answer is no. Moreover, the recent arrival on the Toulouse market of major IT service suppliers usually starts with buyout of one or more local firms with established reputations in the aerospace industry. Buyout means acquisition of a set of capabilities and of personal networks to protect and expand their markets in specific fields such as scientific and engineering calculations for outsourcers such as AIC and avionics suppliers that include Leibherr, Rockwell Collins and Thalès.

We therefore reasonably argue that the centripetal dynamic acting on local players will suffice to sustain their commercial viability and the appeal of individual AIC locations in Europe, assuming that AIC preserves its competitive position and continues to drive the entire production apparatus.

\section{CONCLUSION}

The expansion of AIC programs and the geographical reach of its markets out into the developing countries have triggered a complete restructuring of the geographical distribution of its service suppliers. Long centralized in Toulouse and the cluster of avionics and software suppliers that mushroomed around it, AIC began to decentralize outsourcing in the 1990s to suppliers clustered around its locations in Bristol, Hamburg and Madrid. Today, AIC outsourcing now reaches preferred suppliers in European NATO countries through its preferred subcontractors as it subcontracts directly further afield too.

However, aircraft making requires monitoring and quality control of a level that hamper the speed and extent of outsourcing. At present, outsourcing only covers routine calculations and encoding while engineering services happen in Europe in close cooperation with AIC, which hands down the specifications. Finally, any reduction in the lead time from drawing board to rollout assumes a high degree of responsiveness from geographically-dispersed suppliers that can only be the fruit of a long history of industrial cooperation. Therefore, the risk of erosion in know-how and capabilities is an ongoing concern at AIC; the accompanying concern is the cost benefits of delegating responsibilities to subcontractors and of the positive impact of a new supplier's tender. The ideal balance between in-house work and outsourcing stands or falls on a detailed analysis of the amount of added value to delegate.

Because of AIC, aeronautics is now a major factor in the economies of Bristol, Hamburg, Madrid and Toulouse. Realizing the tensions generated by the global economy, all their institutional, governmental, educational and industrial players are out to protect the appeal of their local AIC clusters and thereby, the prosperity of their metropolises and regions. The present structure of AIC European locations covers a growing range of IT and industrial organization activities, which in turn have attracted service suppliers, especially in hi-tech functions such as design, testing and quality control software. It remains to be seen whether the increasingly stiff competition in today's world aircraft markets will push AIC into a more defensive stance and compromise the efficacy of the model of production clusters that has evolved around its European locations over the years. 
Our study of AIC confirms that the issue of outsourcing goes beyond an evaluation of transaction costs and short-term financial impact. Because of the extended impact over time of the effects of a product or service, outsourcing actually amounts to an investment. Finally, joint supply of a service is extremely sensitive to the quality and features of the outsourcer/subcontractor partnership.

\section{ACKNOWLEDGEMENTS}

This article is an updated version of an earlier French version updated to include comments from participants in the $15^{\text {th }}$ International Conference of RESER, Granada (Spain), 2005.

\section{REFERENCIES}

Amiti Mary, Shang-Jin Wei (2004), "Fear of Outsourcing: Is it Justified", IMF Working Paper 04/186, International Monetary Fund. NOTEZ QUE L'ANGLAIS N'UTILISE QUE “ ET “ POUR LES GUILLEMETS ET QU'IL N'Y A PAS D'ESPACEMENT APRES LES DEUX-POINTS OU POINT-VIRGULES. TRADUIRE AUSSI LES DATES, NOMS DES VILLES ET PAYS

Antonelli C. (1995), "Économie des réseaux : variété et complémentarité » in Rallet A. et Torre A. (Eds), Économie industrielle et économie spatiale, Économica, p 253-272.

Barcet A et Bonamy J, (1994), «Internalisation versus externalisation : valeur et dynamique de l'offre, », Actes du $4^{\circ}$ congrès du RESER, Barcelone, Espagne.

Beckkouche P.(1996), «La nouvelle géographie de l'industrie aéronautique européenne », Paris, L'Harmattan.

Capello R. et Nijkamp P, (1995), «Le rôle des externalités de réseaux dans les performances des firmes et des régions : l'exemple des NTIC » in Rallet A. et Torre A. (Eds), Economie industrielle et économie spatiale, Économica, p 273-293.

Cuñat F et Thomas B,(1994), « Organisation fonctionnelle et recours externe », Actes du $4^{\circ}$ congres RESER, Barcelona, Espagne.

Dumoulin R et Martin A, (200)3, "L'externalisation de la R\&D, une approche exploratoire », Revue française de gestion $\mathrm{n}^{\circ}$ 143, p 55-66.

INSEE, 2004, "Aéronautique, espace et sous-traitance. Résultats de l'enquête 2004 », Les Dossiers de l'INSEE, n¹25, INSEE Midi-Pyrénées, 53 p.

Farell J. et Saloner G., (1986), «Installed Base and Compatibility: Innovation, Product, Preannoucements, and Predation », The American Economic Review, Vol.76, Issue 5, pp 940-955.

Fimbel E, (2003), «Nature et enjeux stratégiques de l'externalisation», Revue Française de Gestion, ${ }^{\circ} 143, \mathrm{p} 27-42$.

Gilly J.P. et Torre A. (Dir.), (2001), "Dynamiques de proximité », L'Harmattan, Collection Emploi, Industrie et Territoire.

Jalabert G., Zuliani J.M., (2005), "L'industrie aéronautique européenne : organisation industrielle et fonctionnement en réseaux", Revue L'Espace Géographique, 2005-2, pp117-123.

Moreau F., (2003), L'entreprise élargie : de nouvelles formes d'organisation, Insep Consulting Ed. 
Muller P., (1989), Airbus, L'ambition européenne, logique d'Etat, logique de marché , Paris, L'harmattan.

Suire R. et Vicente J., (2004), "Les dynamiques de proximité de la net - économie : formation et stabilité des clusters TIC », Actes des $4^{\circ}$ journées de la proximité, Marseille 17 et 18 juin.

Vekeman G, (2006), «L'industrie aérospatiale dans l'Union Européenne », Statistiques en bref, 7/2006, Eurostat

Vicente J., (2005), Les espaces de la net-économie : cluster TIC et aménagement numérique des territoires, Economica, Collection NTIC.

Zuliani J.M. (Dir.), Jalabert G., Leriche F., (2002), "Système productif, réseaux internationaux de villes, dynamiques urbaines: les villes européennes de l'aéronautique ». CIEU-CNRS/Ministère de la Recherche, Programme Cité, Rapport, $343 \mathrm{p}$.

Zuliani J.M., Leriche F., (2004), « Airbus et les recompositions territoriales, Toulouse et Bristol, Géographie et Culture », $\mathrm{N}^{\circ} 48$, p. 60-78.

Zuliani J.M., (2005), «L'agglomération toulousaine, un système productif localisé de la recherche et développement ", in Globalisation, systèmes productifs et dynamiques territoriales, Regards croisés au Québec et dans le Sud-Ouest français (sous la direction de R. Guillaume), L'Harmattan, Collection Géographie en liberté.

\section{Appendix 1. EADS}

Appendix 2 AIC Production Clusters in Europe

Diagram 1. A321 Manufacturers

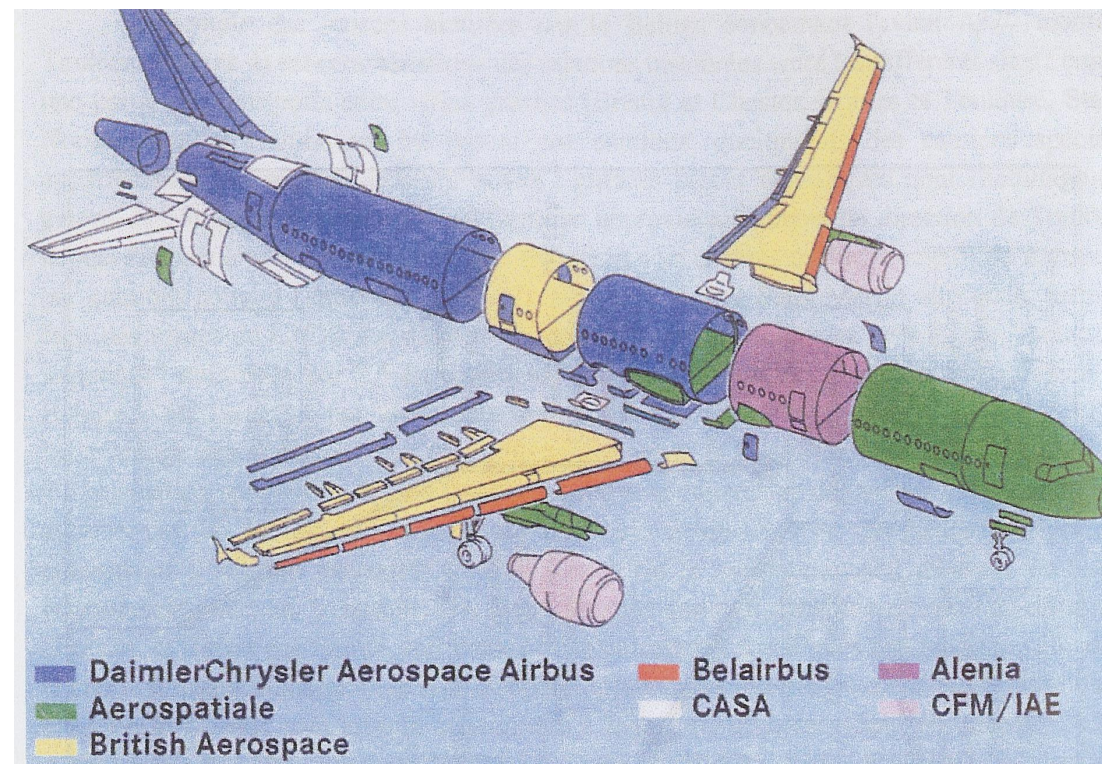


Appendix 1

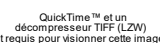


Appendix 2

QuickTime $^{\mathrm{TM}}$ and a

TIFF (LZW) decompressor are needed to see this picture. 